\title{
Comentário ao Artigo "O Ensino e a PeSquisa eM HISTÓRIA ANTIGA NO BRASIL: REFLEXõeS A PARTIR DOS DAdOS dA Plataforma LATTES", DE DOMINIQUE SANTOS, Graziele Kolv E JULIANO JoÃo NAZÁrio.
}

Alex Degan

O artigo de Dominique Santos, Graziele Kolv e Juliano João Nazário apresenta um importante diagnóstico sobre a presença da área acadêmica "História Antiga" no Brasil. Partindo da sistematização de dados fornecidos pelas análises dos currículos (Plataforma Lattes) de 116 docentes atuantes em universidade e faculdades espalhadas por todas as regiões brasileiras, os autores tabularam informações como a distribuição destes especialistas pelo país, o conhecimento de idiomas, os alcances de internacionalização acadêmica e as áreas de interesses (percebidas tanto nos trabalhos de formação - dissertações e teses -, quanto nas pesquisas produzidas). Tais informações revelam-se necessárias para refletirmos sobre o notável crescimento que a área sentiu desde os primeiros passos da institucionalização da História como curso no Ensino Superior. Além desta importante sistematização, os autores ofereceram interpretações dos dados, ponderando sobre a presença ainda tímida de pesquisadores dedicados ao Oriente Antigo e acerca da danosa persistência da dicotomia entre Bacharelado e Licenciatura. Diante de tantos dados que comprovam o crescimento da área, bem como suas futuras potencialidades, cabe apontar uma questão: que História Antiga é esta produzida no Brasil? Indo um pouco além: como esta História Antiga brasileira pode auxiliar no desenvolvimento da História em suas conexões acadêmica, escolar e pública?

Mais do que um exercício de elucubração epistemológica autocentrada, tal questionamento precisa ser refletido pelos antiquistas brasileiros, e com urgência. Sem enfrentarmos tal questão, este crescimento pode ser compreendido apenas como um reflexo ínfimo de um quadro maior de expansão global do Ensino Superior. Nos últimos quarenta anos a matrícula mundial saltou de 13 para 133 milhões de alunos (Mello, 2011, p. 34); durante o mesmo período verificou-se uma forte expansão de Instituições de Ensino Superior (IES) na

\footnotetext{
${ }^{1}$ Professor de História Antiga da UFTM
} 
América Latina, passando de cerca de 160 IES em 1960 para mais de 7500 no começo do século XXI. Tal vertiginosa ampliação ocorreu dentro dos quadros de transformações do capitalismo contemporâneo que cada vez mais direciona a concepção universitária como campo determinado por demandas de mercado (Chauí, 2003). A História, transformada em uma área de formação profissional e de especialização acadêmica, também cresceu neste movimento. No Brasil os cursos de graduação em História passaram de 117, em 1973, para 346 de Licenciatura e 91 de Bacharelado, em 2005 (Araujo, 2015). A História Antiga, ainda compreendida como campo necessário para a formação universitária do historiador, se expandiu neste processo, alcançando os dados sistematizados pelo artigo que comentamos.

Nossa insistência em provocar a reflexão sobre a singularidade da produção de conhecimento histórico oferecida pelos antiquistas brasileiros reside na compreensão de que, mesmo neste quadro complexo de ampliação, a presença desta área não está garantida, carecendo de sinceras meditações em torno de sua legitimidade. Por mais paradoxal que tal movimento se revele, o dedicado esforço científico que historiadores, arqueólogos, filósofos e críticos literários empregaram em estudos sobre a Antiguidade, provando a capacidade de se produzir qualificadas pesquisas na área no Brasil, ainda não sedimentou suficiente prestígio intelectual que auxilie na diluição do que David Wellbery (1988, p. 27 apud Rosa et al., 2011, p. 9) compreendeu como um "territorialismo ansioso, tão comum nos departamentos de ensino das universidades, [...] última defesa da organização romântica do mundo, segundo linhas históricas nacionais”. Esta insuficiência manifestou-se recentemente no ensino escolar de História, um espaço privilegiado para a produção e reprodução de memórias sociais orquestradas pelo Estado (Guarinello, 2013, p. 10) e decisivo para a atuação pública do historiador comprometido "com a tarefa de fazer dos alunos parte ativa do sujeito da história que se aprende e que se faz" (Barros, 2008, p. 20).

Entre 2015 e 2017, o Governo Federal, através do Ministério da Educação, formulou e apresentou três versões de uma Base Nacional Comum Curricular (BNCC). Este processo profundamente tumultuado e envenenado pelas convulsões políticas que violaram a República brasileira teve como um dos protagonistas de suas polêmicas o ensino escolar de História e, no cerne deste, os conteúdos de História Antiga. De uma "diminuição excludente" passou-se para 
uma "presença imposta" da Antiguidade, movimentos que provocaram e provocam acalorados debates dentro e fora da comunidade dos historiadores. As várias frentes destas discussões suscitadas pela BNCC explicitaram velhas questões ainda mal resolvidas: a identificação dos estudos da Antiguidade com os fundamentos da uma compreensão eurocêntrica da História e do mundo, a necessidade destes conteúdos curriculares cederem espaço aos compreendidos como mais prementes para os brasileiros, e a falta de clareza quanto aos "objetos de aprendizagem fundamentais ao aprendizado histórico" (Freitas de Oliveira, 2016). Compreendemos que o crescimento da presença dos antiquistas nas IES brasileiras precisa se conectar com estas querelas, amadurecendo e superando estes embates.

Desde o final da década de 60 do século passado, com os movimentos de emergência das periferias europeias, de descolonização, de meditações sobre o gênero, sobre a sexualidade e a etnicidade, historiadores começaram, como apontou Patrick Geary (2005, p. 27), a denunciar toda espécie de lixo tóxico imperialista, racista e nacionalista que contaminavam os campos férteis da historiografia. Neste processo, antiquistas empreenderam reflexões e autocríticas afiadas, procurando repensar e redefinir suas áreas de pesquisa e ensino na contramão do etnocentrismo imperialista (Bernal, 2003; Beard, 2013; Vlassopoulos, 2007; Hartog, 2003; Guarinello, 2003; Hingley, 2010). Assim, até o final do século XX, muitos foram os autores que literalmente "soltaram o verbo" nos usos e abusos que se valeram da História Antiga para justificar o injustificável, pois, como bem assinalou Moses Finley, "não eram os antigos que proporcionavam os valores, mas os valores que selecionavam os antigos" (Finley, 1973). Infelizmente, o gigantesco potencial suscitado por estas contribuições segue ignorado por colegas que insistem na identificação da Antiguidade como matriz de uma História exclusivamente eurocêntrica.

Este ponto é extremamente relevante, já que a própria crítica ao conceito de eurocentrismo se beneficiaria sobremaneira não apenas destes trabalhos críticos dos antiquistas, como dos próprios estudos contemporâneos sobre a Antiguidade. Compreendendo a noção de eurocentrismo "não só como as várias formas de influência política, econômica e social da Europa no globo, mas sobretudo como uma remissão ao enraizamento dos conceitos e valores que operam na ciência e em outras formas de enxergarmos o mundo" (Santos et al., 
2017, p. 163), a própria História (enquanto disciplina acadêmica) e seu ensino escolar (como preocupação singular dos Estados Nacionais modernos) estariam comprometidos.

Uma maneira inteligente de reverter este "privilégio epistêmico" (Seth, 2013, p. 187) encontra-se no exame de "outras representações do passado, conceito que pode incluir mitos, épicos e lendas em uma relação sem hierarquias com a escrita da história ocidental" (Santos et al., 2017, p. 179). O estudo da Antiguidade é extremamente profícuo em oferecer tais exercícios, proporcionando uma riquíssima economia de códigos inter-relacionada, como encontramos nas crônicas mesopotâmicas (Glassner, 1993, p. 20-21) e nas narrações deuteronomistas judaicas (Römer, 2008). Até as narrativas históricas gregas e romanas apresentam volumosos e férteis canais que as ligam ao mito e à epopeia (Pires, 1999; Beard, 2016, p. 103-104). Outro aspecto interessante reside na seguinte constatação: as áreas centrais da Antiguidade (como o Centro-Sul italiano, o Egeu, porções do Norte da África, o vale do Nilo, o Levante, o litoral da Ásia Menor, a Mesopotâmia e o planalto iraniano) não coincidem com o espaço nevrálgico da compreensão eurocêntrica. A Europa do Norte e outras regiões que ostentam a dianteira do Ocidente, como os Estados Unidos e a Austrália, eram regiões periféricas, marginais ou absolutamente ignoradas pelas dinâmicas do Mundo Antigo. Assim, como notou Norberto Guarinello (2003, p. 52), mesmo as formulações eurocêntricas da História Antiga não conseguem ser, "em absoluto, a História da Europa". Estas ambiguidades e incongruências atuantes em diversas gramáticas de tempos desvelam as inúmeras camadas de historicidade que a alargada temporalidade da Antiguidade pode nos ofertar (Gaddis, 2003, p. 18). Como cada época constrói sua própria Roma (Beard, 2016, p. 19), eis aqui um afortunado instrumento historiográfico de aprendizado histórico!

Outra contribuição historiográfica, profundamente relacionada com o que discutimos até agora, encontra-se na perspectiva aberta por The Corrupting Sea, de Peregrine Horden e Nicholas Purcell (2000). Embebidos com temperos braudelianos, a obra incorpora reflexões socioambientais nutridas no diálogo com a Geografia e destaca o que os autores identificam como uma singularidade mediterrânica: o estudo das microrregiões socioambientais e de suas interrelações, ações que caracterizariam a unidade humana desta história integrada em uma rede complexa de conexões alinhavadas principalmente pelo mar. Esta 
perspectiva apresenta uma análise histórica alternativa ao tradicional recorte fornecido pelo enquadramento político e pelo Estado Nação, ressaltando os multisseculares processos de interação e integração (sem minimizar a exclusão e o domínio) vivenciados por distintos grupos e etnias. Um imenso corredor afroeuro-asiático delineia com contornos precisos o campo de uma História deslocada da fronteira eurocêntrica ou nacional, atenção extremamente necessária e válida neste alvorecer do século XXI, da mundialização do planeta conectado pela internet e por mercados geradores de riqueza e de pobreza em escalas inimagináveis (Guarinello, 2013, p. 12).

Estas contribuições contemporâneas dos antiquistas brasileiros são essenciais em múltiplos aspectos. No campo da formação profissional e intelectual do historiador, elas auxiliam em uma saudável internacionalização da historiografia. Como demonstrado no artigo de Santos, Kolv e Nazário, os antiquistas aprofundam os vínculos internacionais da Ciência brasileira, atuando tanto em estágios de pesquisa no exterior quanto na introdução de temas e abordagens historiográficas importantes. O próprio campo historiográfico, que se inicia com os "quase 250 anos desde que Edward Gibbon escreveu Declínio e Queda do Império Romano" (Beard, 2016, p. 18), acumula um inestimável trabalho morto de crítica historiográfica, lastro necessário para qualquer formação responsável em História. Esta não é uma particularidade desprezível, pois desde a fundação dos primeiros cursos de graduação de História no Brasil (década de 30 do século XX), inovações conceituais, metodológicas e historiográficas foram introduzidas aqui pela ação de professores universitários estrangeiros ou com sólidos vínculos em academias estrangeiras (Capelato et al., 1994, p. 352). Por exemplo, a expansão do escopo documental, com o uso de textos literários e dramatúrgicos, a análise da iconografia e da cultura material, foram ações precocemente praticadas entre os antiquistas (Castilho, 1963; Starzynsli, 1961; Sarian, 1983-1984). Estas contribuições são importantes no fomento de uma cultura historiográfica ampla que produza um campo intelectual da História mais dilatado do que os providos pelos embates políticos e identitários inerentes ao nosso ofício.

No campo do ensino e da aprendizagem da História na Educação Básica e na esfera pública compreendemos que os aportes dos antiquistas também são necessários para uma apreensão mais profunda da vida humana. 
Compartilhamos o entendimento de Jörn Rüsen, para quem "a história é enraizada nas necessidades sociais para orientar a vida dentro da estrutura tempo" (2011, p. 25), possibilitando um "agir no mundo" que exige quadros sociais de memória e de referências organizados numa gramática de tempo que conjuga certa perspectiva de passado com uma expectativa de futuro, nos impelindo a interpretar, ler e compreender o presente.

A História possui, então, um aspecto prático, ligado à consciência histórica, "um conjunto coerente de operações mentais que definem a peculiaridade do pensamento histórico e a função que ele exerce na cultura humana" (Rüsen, 2011, p. 37). Para Rüsen (2010, p. 78-79),

a consciência histórica não é algo que os homens podem ter ou não - ela é algo universalmente humano, dada necessariamente junto com a intencionalidade da vida prática dos homens. A consciência histórica enraíza-se, pois, na historicidade intrínseca à própria vida humana prática. Essa historicidade consiste no fato de que os homens, no diálogo com a natureza, com os demais homens e consigo mesmos, acerca do que sejam eles próprios e seu mundo, têm metas que vão além do que é o caso.

Assim, a consciência histórica de uma sociedade não é nutrida apenas pelas histórias dos historiadores. As mídias contemporâneas, a vida social, as religiões, as artes e um quadro amplo de ações coletivas contam na constituição de nossa cultura histórica. Neste contexto entendemos que, para os antiquistas brasileiros, a chave encontra-se agora na reflexão sobre a pertinência ou não da Antiguidade no horizonte de nossas consciências históricas. Este segue sendo o nó górdio que embalou e ainda embala a presença dos antiquistas no Brasil. Desatá-lo é nossa tarefa.

No caso brasileiro, temas da Antiguidade estão presentes e fincados em muitos espaços, desde o exemplo óbvio da língua portuguesa até as recentes produções televisivas sobre temas bíblicos. As Catilinárias dirigidas pela Polícia Federal contra políticos corruptos (LEITÃO, 2015) e o suntuoso Templo de Salomão erigido no Brás paulistano nos conferem uma estranha intimidade com este universo. Aproximar estas alteridades, oferecer referências interpretativas assentadas em moderna historiografia e dialogar com esta cultura histórica cotidiana fundamenta essencial objeto de aprendizagem, tanto na Educação Básica como na História Pública. Saber trabalhá-la não mais como eixo basilar de uma linha histórica evolutiva universal, mas sem "simplesmente virar a cara ao 
passado distante" (Beard, 2016, p. 17), é um dos principais desafios dos historiadores, antiquistas ou não.

Por fim, acreditamos que a História Antiga enquanto forma intelectual ainda nos é cara e necessária. Com ela e através dela podemos refinar, no campo do ensino, os instrumentos próprios da História Ciência, ou seja, o pensar historicamente. Esta História tão recuada e, ao mesmo tempo, tão presente, nos auxilia a demonstrar os caminhos da historicidade (todas as coisas resultam de um processo histórico e continuam na história), da relatividade (ideia de que todos os pontos de vista são relativos a determinados lugares de origens), da consciência historiográfica (de que o historiador só pode construir os conhecimentos de suas pesquisas considerando os conhecimentos anteriores atinentes ao seu tema), e da alteridade (o espaço para o contato com o "outro", que no caso da Antiguidade se coloca de forma quase absoluta). História Antiga aqui é uma ferramenta intelectual indispensável e um quadro de referências que continua a escorar parte significativa de nossa cultura política e dos mitos que fazem parte do cadinho de fundição do Brasil. Como bem apontou Mario Liverani, tal patrimônio deve ser "objeto de esclarecimentos e críticas, e que não devem ser ignorados ou simplesmente eliminados de nossa memória" (Liverani, 2016, p. 30). Perder este campo seria empobrecer sobremaneira nosso horizonte historiográfico, atuando contra a perspectiva de erudição que deve fomentar intimamente a formação de um bom professor e a ação crítica frente aos campos que alimentam a consciência histórica do brasileiro. A expansão do campo profissional de atuação dos antiquistas em nossas universidades precisa acelerar reflexões desta natureza. Assim, quem sabe, deste rincão extremo-ocidental latino-americano (Bancarali Molina, 2007, p. 32) nós poderemos meditar sobre a "Esfinge" de Darcy Ribeiro, refletindo com algum entusiasmo acerca de nossas singularidades: "Isto significa que, apesar de tudo, somos uma província da civilização ocidental. Uma nova Roma, uma matriz ativa da civilização neolatina. Melhor que as outras, porque lavada em sangue negro e em sangue índio, cujo papel, doravante, menos que absorver europeidades, será ensinar o mundo a viver mais alegre e mais feliz" (Ribeiro, 2006, p. 242). 


\section{Referências Bibliográficas}

Araujo, Valdei Lopes de. Pós-graduação, avaliação e o futuro da (sem) história. 2015. Disponível em:

<http://nehmfimdahistoria.blogspot.com.br/2015/o5/pos-graduacao-

avaliacao-e-o-futuro-da.html > . Acesso em: 11 abr. 2017.

Bancarali Molina, Alejandro. Orbe Romano e Imperio Global: La romanización desde Augusto a Caracalla. Santiago: Editorial Universitaria, 2007.

Barros, Carlos. Propuestas para el nuevo paradigma educativo de la Historia. Revista de História (São Paulo), n. 158, 2008, p. 09-41.

Beard, Mary. Confronting the Classics: Traditions, Adventures, and Innovations. London: Liveright, 2013.

Beard, Mary. SPQR: uma História da Roma Antiga. Lisboa: Bertrand, 2016.

Bernal, Martin. A imagem da Grécia Antiga como uma ferramenta para o colonialismo e para a hegemonia europeia. In: FUNARI, Pedro Paulo de Abreu (org.). Repensando o Mundo Antigo. Col. Textos Didáticos, 49. Campinas: IFCH/UNICAMP, 2003.

Capelato, Maria Helena Rolim; Glezer, Raquel; Ferlini, Vera Lúcia Amaral. Escola uspiana de História. Estudos Avançados (São Paulo), 8 (22), 1994, p. 349-358.

Castilho, Ataliba T. de. Robert Henri Aubreton. Alfa: Revista de Linguística (Marília), v. 4, 1963, p. 133-137.

Chaú, Marilena. A universidade pública sob nova perspectiva. Revista Brasileira de Educação, n. 24, 2003, p. 05-15.

Finley, Moses I. La crisis en las Lenguas Clásicas. In: PLUMB, J. H. (org.). Crisis en las Humanidades. Barcelona: Planeta, 1973.

Freitas De Oliveira, Itamar. Sobre História Antiga e Medieval outra vez. 2016. Disponível em:

<https://didaticadahistoria.wordpress.com/2016/03/12/sobre-historia-antigae-medieval-outra-vez/> . Acesso em: 11 abr. 2017.

Gaddis, John Lewis. Paisagens da História: Como os historiadores mapeiam o passado. Rio de Janeiro: Campus, 2003.

Geary, Patrick J. O Mito das Nações: A invenção do nacionalismo. São Paulo: Conrad, 2005.

Glassner, Jean-Jacques. Chroniques Mésopotamiennes. Paris: Les Belles Lettres, 1993 .

Guarinello, Norberto Luiz. História Antiga. São Paulo: Contexto, 2013.

Uma morfologia da História: As formas da História Antiga. Politeia:

História e Sociedade (Vitória da Conquista), vol. 3, n. 1, 2003, p. 41-61.

Hartog, François. Os antigos, o passado e o presente. Brasília: Editora da UnB, 2003.

Hingley, Richard. O Imperialismo Romano: Novas perspectivas a partir da Bretanha. São Paulo: Annablume, 2010. 
Horden, Peregrine; Purcell, Nicholas. The Corrupting Sea: A Study of Mediterranean History. Oxford: Blackwell, 2000.

Leitão, Matheus. Nome de operação faz referência a político que queria derrubar governo romano. 2015. Disponível em:

<http://g1.globo.com/politica/blog/matheus-leitao/post/nome-de-operacaose-refere-discursos-contra-politico-que-queria-derrubar-o-governo.html > .

Acesso em: 11 abr. 2017.

LiveranI, Mario. Antigo Oriente: História, Sociedade e Economia. São Paulo: EDUSP, 2016.

Mello, Alex Fiúza de. Globalização, sociedade do conhecimento e educação superior: Os sinais de Bolonha e os desafios do Brasil e da América Latina. Brasília: Editora UnB, 2011.

Pires, Francisco Murari. Mithistória. São Paulo: Humanitas, 1999.

Ribeiro, Darcy. O Povo Brasileiro: A formação e o sentido do Brasil. São Paulo: Companhia das Letras, 2006.

Römer, Thomas. A chamada história deuteronomista: Introdução sociológica, histórica e literária. Petrópolis: Vozes, 2008.

Rosa, Cláudia Beltrão da; MARQUES, Juliana Bastos; TACLA, Adriene Baron; MENDES, Norma Musco (orgs). A busca do Antigo. Rio de Janeiro: Nau Editora, 2011.

Rüsen, Jörn. Razão Histórica. Teoria da História: Fundamentos da ciência histórica. Brasília: Editora da UnB, 2010.

Didática da história: Passado, presente e perspectiva a partir do caso alemão. In: SCHMIDT, Maria Auxiliadora; BARCA, Isabel; MARTINS, Estevão de Resende (orgs.). Jörn Rüsen e o Ensino de História. Curitiba: Editora UFPR, 2011.

Santos, Pedro Afonso Cristovão dos; NICODEMO, Thiago Lima; PEREIRA, Mateus Henrique de Faria. Historiografias periféricas em perspectiva global ou transnacional: Eurocentrismo em questão. Estudos Históricos (Rio de Janeiro), vol. 30, n. 60, 2017, p. 161-186.

Sarian, Haiganuch. Arqueologia Clássica em museus brasileiros. Humanitas (Coimbra), 35-36, 1983-1984, p. 421-426.

Seth, Sanjay. Razão ou raciocínio? Clio ou Shiva? História da Historiografia (Ouro Preto), n. 11, 2013, p. 173-189.

Starzynsli, Gilda Maria Reale. Língua e Literatura Grega: Origens. Estudos Avançados (São Paulo), 8 (22), 1994, p. 395-400.

Vlassopoulos, Kostas. Unthinking the Greek Polis: Ancient Greek History Beyond Eurocentrism. Cambridge/New York: Cambridge University Press, 2007. 